\title{
Geoglobus acetivorans sp. nov., an iron(III)-reducing archaeon from a deep-sea hydrothermal vent
}

\author{
G. B. Slobodkina ${ }^{1,{ }^{*}}$, T. V. Kolganova ${ }^{2}$, J. Querellou ${ }^{3}$, E. A. Bonch-Osmolovskaya ${ }^{1}$ and A. I. Slobodkin ${ }^{1}$ \\ ${ }^{1}$ Winogradsky Institute of Microbiology, Russian Academy of Sciences, Prospect 60-letiya Oktyabrya 7/2, 117312 \\ Moscow, Russia \\ ${ }^{2}$ Bioengineering Center, Russian Academy of Sciences, Prospect 60-letiya Oktyabrya 7/1, 117312 Moscow, \\ Russia \\ ${ }^{3}$ UMR 6197, Microbiology of Extreme Environments, Ifremer, Centre de Brest, 29280 Plouzané, France
}

*: Corresponding author : G. B. Slobodkina, email address : gslobodkina@mail.ru

\begin{abstract}
:
A hyperthermophilic, anaerobic, dissimilatory $\mathrm{Fe}(\mathrm{III})$-reducing, facultatively chemolithoautotrophic archaeon (strain $\mathrm{SBH}^{\top}$ ) was isolated from a hydrothermal sample collected from the deepest of the known World Ocean hydrothermal fields, Ashadze field ( $\left.1^{\circ} 58^{\prime} 21^{\prime \prime} \mathrm{N} 4^{\circ} 51^{\prime} 47^{\prime \prime} \mathrm{W}\right)$ on the MidAtlantic Ridge, at a depth of $4100 \mathrm{~m}$. The strain was enriched using acetate as the electron donor and $\mathrm{Fe}$ (III) oxide as the electron acceptor. Cells of strain $\mathrm{SBH} 6^{\top}$ were irregular cocci, $0.3-0.5 \mu \mathrm{m}$ in diameter. The temperature range for growth was $50-85^{\circ} \mathrm{C}$, with an optimum at $81{ }^{\circ} \mathrm{C}$. The $\mathrm{pH}$ range for growth was 5.0-7.5, with an optimum at $\mathrm{pH}$ 6.8. Growth of $\mathrm{SBH}^{\top}$ was observed at $\mathrm{NaCl}$ concentrations ranging from 1 to $6 \%(\mathrm{w} / \mathrm{v})$ with an optimum at $2.5 \%(\mathrm{w} / \mathrm{v})$. The isolate utilized acetate, formate, pyruvate, fumarate, malate, propionate, butyrate, succinate, glycerol, stearate, palmitate, peptone and yeast extract as electron donors for Fe(III) reduction. It was also capable of growth with $\mathrm{H}_{2}$ as the sole electron donor, $\mathrm{CO}_{2}$ as a carbon source and $\mathrm{Fe}(\mathrm{III})$ as an electron acceptor without the need for organic substances. Fe(III) [in the form of poorly crystalline Fe(III) oxide or Fe(III) citrate] was the only electron acceptor that supported growth. 16S rRNA gene sequence analysis revealed that the closest relative of the isolated organism was Geoglobus ahangari $234^{\top}(97.0 \%)$. On the basis of its physiological properties and phylogenetic analyses, the isolate is considered to represent a novel species, for which the name Geoglobus acetivorans sp. nov. is proposed. The type strain is $\mathrm{SBH}^{\top}$ $\left(=\mathrm{DSM} 21716^{\top}=\right.$ VKM B-2522 $\left.{ }^{\top}\right)$.
\end{abstract}

Abbreviations: AQDS, 9,10-anthraquinone-2,6-disulfonate; DGGE, denaturing gradient gel electrophoresis 
Iron minerals are abundant in the deep-sea hydrothermal vents. The surfaces of active chimneys are frequently covered with deposits of iron oxides at different oxidative states and amount of iron in hydrothermal fluid can reach molar concentrations. Thus, deep-sea hydrothermal vents can provide ecological niche for Fe(III)-reducing micro-organisms (Slobodkin, 2001). However, only few thermophilic Fe(III)-reducers were isolated from this environment. Currently, thermophilic and hyperthermophilic iron-reducing micro-organisms recovered from deep-sea habitats include two species of Bacteria, Geothermobacter ehrlichii (Kashefi et al., 2003) and Deferribacter abyssii (Miroshnichenko et al., 2003) and three representatives of Archaea, Thermococcus sp. SN531 (Slobodkin et al., 2001), Geoglobus ahangari (Kashefi et al., 2002) and Aciduliprofundum boonei (Reysenbach et al., 2006).

In this article, we report the isolation and characterization of the novel hyperthermophilic $\mathrm{Fe}(\mathrm{III})$-reducing archaeon from the deepest of the known World Ocean hydrothermal field.

Strain $\mathrm{SBH} 6^{\top}$ was isolated from a sample of the fragment of the hydrothermal chimney-like structure. The sample was collected in March 2007 during the SERPENTINE cruise at the Ashadze hydrothermal field (12 58' 21" N, $4451^{\prime} 47$ " W) on the Mid-Atlantic Ridge at a depth of $4100 \mathrm{~m}$. For the samples collection sterilized microbiological boxes filled with sterile freshwater were prepared onboard. Active chimney samples were collected by the ROV Victor. On site, after opening the box lid, the freshwater was replaced by in situ seawater, the chimney fragment introduced and the lid closed. All following operations were done onboard in sterile conditions. Boxes with samples were stored at $4^{\circ} \mathrm{C}$. An enrichment culture was initiated by inoculation of $10 \%(\mathrm{w} / \mathrm{v})$ of the sample into anaerobically prepared, bicarbonatebuffered, sterile $\left(135^{\circ} \mathrm{C}, 1 \mathrm{~h}\right)$ liquid medium with acetate $(18 \mathrm{mM})$ as an electron donor and poorly crystalline $\mathrm{Fe}(\mathrm{III})$ oxide $\left(90 \mathrm{mmol} / \mathrm{I}^{-1}\right)$ as an electron acceptor. Medium composition and preparation techniques were described earlier (Slobodkin et al., 1999a); the medium was additionally supplemented with $\mathrm{NaCl}\left(18 \mathrm{~g} \mathrm{l}^{-1}\right)$ and $\mathrm{MgCl}_{2}\left(4 \mathrm{~g} \mathrm{l}^{-1}\right)$ to increase the salinity. After three subsequent transfers and following serial 10 -fold dilutions in the same medium at $65^{\circ} \mathrm{C}$ two morphological types of cells were observed in the highest positive dilution $\left(10^{-5}\right)$ : rods and cocci. To obtain coccoid-shaped micro-organism further cultivation was carried out at $82^{\circ} \mathrm{C}$. After two transfers at $82^{\circ} \mathrm{C}$ the rods were not observed neither at $82^{\circ} \mathrm{C}$ nor at $65^{\circ} \mathrm{C}$ and only coccoid-shaped cells were present in the enrichment. Acetate $(4.5 \mathrm{mM})$ consumption in enrichments measured by gas chromatography reached $80 \%$. The attempts to obtain separate colonies in agar-blocks or by roll-tube method (Hungate, 1969) were unsuccessful either at $82^{\circ} \mathrm{C}$ or at $65^{\circ} \mathrm{C}$ with $1 \%$ of GELRITE gellan gum or with $2 \%$ of agar as solidifying agent in the medium correspondingly. Then the enrichment was subsequently transferred five times in lithoautotrophic conditions with molecular hydrogen as an electron donor, poorly crystalline $\mathrm{Fe}(\mathrm{III})$ oxide as the electron acceptor and $\mathrm{CO}_{2}$ as the carbon source at $82^{\circ} \mathrm{C}$ and after that serially diluted at the same conditions. The isolate from the highest dilution that exhibited $\mathrm{Fe}(\mathrm{III})$ reduction $\left(10^{-6}\right)$, was considered as a pure culture and was designated strain $\mathrm{SBH}^{\top}$. Denaturing gradient gel-electrophoresis (DGGE) of the strain $\mathrm{SBH}^{\top}$ grown on the media containing acetate $(18 \mathrm{mM})$ or peptone $\left(10 \mathrm{~g} \mathrm{l}^{-1}\right)$ as electron donor and poorly crystalline $\mathrm{Fe}(\mathrm{III})$ oxide $\left(90 \mathrm{mmol} / \mathrm{I}^{-1}\right)$ as electron acceptor in the presence of yeast extract $\left(0.02 \mathrm{~g} \mathrm{l}^{-1}\right)$ revealed the single band in each case and thus confirmed the purity of the culture. Complete 16S rRNA gene sequences of the strain $\mathrm{SBH}^{\top}$ grown with acetate or peptone were identical. Physiological studies on substrate and electron acceptor utilization, temperature, $\mathrm{pH}$ and salinity ranges for growth, light and electron microscopy, analytical techniques (Fe(II) and acetate concentrations), DNA extraction were performed as described previously (Slobodkin et al., 1999a). Growth of the strain with poorly crystalline Fe(III) was determined by direct cells count using light microscopy after dissolving the iron precipitate in solution of ammonium oxalate (28 g l-1) / oxalic acid (15 g l-1) (Lovley and Phillips, 1988). pH measurements and $\mathrm{pH}$-meter calibration were carried out at $60^{\circ} \mathrm{C}$. $16 \mathrm{~S}$ rRNA gene amplification, sequencing and sequence analysis were done as described previously (Zavarzina et al., 2002). 16S rRNA gene fragments for DGGE were obtained using PCR with primers Uni515F (Lane, 1991) withGC-clamp (Muyzer et al., 1993) at the 5' end and 915R (Casamayor et al., 2002). DGGE was performed as described (Muyzer et al., 1997) with 
denaturating gradient ranging from $35 \%$ to $65 \%$ (100\% denaturant contains $7 \mathrm{M}$ urea and $40 \%$ formamide).

Cells of strain $\mathrm{SBH}^{\top}$ were regular to irregular cocci, about 0.3-0.5 $\mu \mathrm{m}$ in diameter, usually arranged as single cells, flagella were not observed. The temperature range for growth of strain $\mathrm{SBH} 6^{\top}$ was $50-85^{\circ} \mathrm{C}$, with an optimum at $81^{\circ} \mathrm{C}$. No growth was detected at $90^{\circ} \mathrm{C}$ or at $46^{\circ} \mathrm{C}$ after incubation for 3 weeks. The $\mathrm{pH}$ range for growth was $\mathrm{pH}$ 5.0-7.5, with an optimum at $\mathrm{pH}$ 6.8. No growth was noticed at $\mathrm{pH} 4.5$ or 8.0. Growth of strain $\mathrm{SBH}^{\top}$ was observed at $\mathrm{NaCl}$ concentrations ranging from 1.0 to $6.0 \%(\mathrm{w} / \mathrm{v})$ with an optimum at $2.5 \%(\mathrm{w} / \mathrm{v})$, but no growth was evident at 0 and $7.0 \% \mathrm{NaCl}(\mathrm{w} / \mathrm{V})$. Poorly crystalline $\mathrm{Fe}(\mathrm{III})$ oxide was reduced to black magnetic precipitate with high $\mathrm{Fe}$ (II) content. No changes in color and amount of precipitate were observed in uninoculated controls containing poorly crystalline $\mathrm{Fe}(\mathrm{III})$ oxide during the incubation period at $82^{\circ} \mathrm{C}$. Strain $\mathrm{SBH}^{\top}$ grew and reduced $\mathrm{Fe}(\mathrm{III})$ with acetate $(4.5$ or $18 \mathrm{mM}$ ), formate, pyruvate, fumarate, malate, propionate, butyrate, succinate, glycerol, (20 $\mathrm{mM}$ each), stearate, palmitate (0.5-1.0 mM each), peptone, yeast extract, $\left(10 \mathrm{~g} \mathrm{l}^{-1} \mathrm{each}\right)$. During growth with acetate $(4.5 \mathrm{mM})$ and $\mathrm{Fe}(\mathrm{III})$ in the absence of yeast extract, $80 \%$ of acetate were consumed and a ratio of $\mathrm{Fe}(\mathrm{II})$ produced to acetate consumed was 7.5. Strain $\mathrm{SBH} 6^{\top}$ also grew with molecular hydrogen as the sole electron donor for $\mathrm{Fe}(\mathrm{III})$ reduction and $\mathrm{CO}_{2}$ as the carbon source. No organic carbon source was required for growth on hydrogen. There was no $\mathrm{Fe}(\mathrm{III})$ reduction or cell growth in the absence of added hydrogen. Strain $\mathrm{SBH}^{\top}{ }^{\top}$ was not able to utilize lactate $(25 \mathrm{mM})$, L-alanine, glycine $(20 \mathrm{mM}$ each), L-proline, arginine, serine, glutamine, asparagine, L-cysteine, aspartic acid, glutamic acid (10 mM each), methanol, ethanol, benzoate (20 mM each) with poorly crystalline $\mathrm{Fe}(\mathrm{III})$ oxide as an electron acceptor. Besides poorly crystalline $\mathrm{Fe}(\mathrm{III})$ oxide, strain $\mathrm{SBH}^{\top}$ also could grow with $\mathrm{Fe}(\mathrm{III})$ citrate $(10 \mathrm{mM})$ as the electron acceptor but cells yield and $\mathrm{Fe}(\mathrm{III})$ reduction was lower. $\mathrm{Fe}$ (III) citrate was not completely reduced, no more than 5-6 mM of $\mathrm{Fe}$ (II) was formed. Several attempts to grow strain $\mathrm{SBH}^{\top}$ on a variety of commonly considered electron acceptors (including sulfate $(14 \mathrm{mM})$, thiosulfate $(20 \mathrm{mM})$, elemental sulfur $\left(10 \mathrm{~g} \mathrm{I}^{-1}\right)$, nitrate (10 mM), fumarate (20 mM), Mn(IV)oxide (25 mM), 9,10-anthraquinone 2,6-disulfonate (AQDS (20 mM)) and oxygen (2 or $20 \%, \mathrm{v} / \mathrm{v})$ ) other than poorly crystalline Fe (III) oxide (90 $\left.\mathrm{mmol} / \mathrm{l}^{-1}\right)$ and $\mathrm{Fe}(\mathrm{III})$ citrate $(10 \mathrm{mM})$ using acetate $(18 \mathrm{mM}), \mathrm{H}_{2}\left(\right.$ as $\mathrm{H}_{2}: \mathrm{CO}_{2}, 80: 20 \%$, v/v, 101 $\mathrm{kPa})$, lactate $(25 \mathrm{mM})$, butyrate $(20 \mathrm{mM})$ or glycerol $(20 \mathrm{mM})$ were unsuccessful.

A comparison of 1417 nucleotides of $16 \mathrm{~S}$ rRNA gene sequence of strain $\mathrm{SBH}^{\top}$ with those available in GenBank database showed that strain $\mathrm{SBH}^{\top}$ had the highest identity with Geoglobus ahangari $234^{\top}$ (97.0\%) (Fig.1). Only 16S rRNA sequences of the type strains of validly published species were included in the analyses. The levels of 16S rRNA gene sequence similarity with other members of the order Archaeoglobales were 94.9-95.3\%. The trees constructed by maximum likelihood and by maximum parsimony algorithms displayed the same topology (data not shown). Transversion analysis (Woese et al., 1991) did not affect the phylogenetic position of the new strain.

The new hyperthermophilic isolate described in this report, capable of reduction of $\mathrm{Fe}(\mathrm{III})$ was recovered from the environmental sample using acetate as the electron donor for initial enrichment. Acetate is one of the major metabolic products of organic matter decomposition under anaerobic conditions and it could be produced during fermentation by many hyperthermophiles (Slobodkin et al., 1999b). For a long time there was no data demonstrating anaerobic acetate degradation by hyperthermophiles. Then this ability was shown for two micro-organisms, Ferroglobus placidus and Geoglobus ahangari (Tor et al., 2001), however none of these strains was initially enriched and obtained into pure culture with acetate as the electron donor. Final purification of the isolate SBH6 was carried out in lithoautotrophic conditions with molecular hydrogen as the electron donor since colonies on the medium with acetate were not formed. However, already in enrichments cultivated in hyperthermophilic conditions only one morphological type of cells was observed. Since the same extent of acetate consumption and $\mathrm{Fe}(\mathrm{III})$ reduction was detected before and after 
purification in autotrophic conditions, we can assume that strain SBH6 was responsible for acetate utilization in initial enrichments. Therefore, SBH6 is the first hyperthermophilic microorganism enriched on acetate as the electron donor. At the present, the order Archaeoglobales includes one family Archaeoglobacae consisnting of three genera: Archaeoglobus, Ferroglobus and Geoglobus (Cole et al., 2007). The genus Geoglobus is represented by the sole species, Geoglobus ahangari (Kashefi et al., 2002) isolated from a deep-sea hydrothermal sample from Guaymas Basin, Gulf of California. The isolate $\mathrm{SBH} 6^{\top}$ shares many phenotypic features with the described representative of this genus. First of all, it is the inability to use for growth the electron acceptors other than Fe(III), preferable insoluble $\mathrm{Fe}$ (III) oxide. Both micro-organisms grow poorly in media with soluble form of $\mathrm{Fe}$ (III) (Fe(III) citrate) as an electron acceptor. There is practically no difference in electron donors utilization, including anaerobic oxidation of long-chain fatty acids and the ability to grow chemolithoautotrophically. Significant differences between $G$. ahangari and the strain $\mathrm{SBH} 6^{\top}$ are noticed in growth temperatures. Strain $\mathrm{SBH}^{\top}$ grows at $50^{\circ} \mathrm{C}$ and it does not grow at $85^{\circ} \mathrm{C}$ and above whereas the low growth limit for $\mathrm{G}$. ahangari is $65^{\circ} \mathrm{C}$ and it is able to grow up to $90^{\circ} \mathrm{C}$. The optimal growth temperatures also differ for $7^{\circ} \mathrm{C}$ being $88^{\circ} \mathrm{C}$ for $\mathrm{G}$. ahangari and $81^{\circ} \mathrm{C}$ for the strain $\mathrm{SBH} 6^{\top}$. In addition, analysis of $16 \mathrm{~S}$ rRNA gene sequences revealed considerable phylogenetic distance between $G$. ahangari and isolate $\mathrm{SBH}^{\top}$. Thus, phylogenetic and physiological properties clearly differentiate strain $\mathrm{SBH} 6^{\top}$ from the closest relative, G. ahangari. According to the opinion of Judicial Commission of the International Committee for Systematics of Prokaryotes (Judicial Commission of the International Committee for Systematics of Prokaryotes, 2008) G. ahangari is not validly published since it is deposited only in one collection of micro-organisms. However, we hope that it will be validated and we propose strain $\mathrm{SBH}^{\top}$ as the type strain of the new species, Geoglobus acetivorans, the second species of the genus Geoglobus.

\section{Description of Geoglobus acetivorans sp.nov.}

Geoglobus acetivorans (a.ce.ti.vo'rans. L. neut. n. acetum, vinegar or acetic acid; L. part. adj. vorans devouring; N.L. part. adj. acetivorans, vinegar consuming). Cells are regular to irregular cocci, 0.3-0.5 $\mu \mathrm{m}$ in diameter, occurring singly. The temperature range for growth is $50-85^{\circ} \mathrm{C}$, with an optimum at $81^{\circ} \mathrm{C}$. The $\mathrm{pH}$ range for growth is $5.0-7.5$, with an optimum at $\mathrm{pH}$ 6.8. Growth occurs at $\mathrm{NaCl}$ concentrations ranging from 1.0 to $6.0 \%(\mathrm{w} / \mathrm{v})$ with an optimum at $2.5 \%(\mathrm{w} / \mathrm{v})$. Anaerobic. Capable of chemolithoautotrophic growth using molecular hydrogen as an electron donor, ferric iron as electron acceptor and $\mathrm{CO}_{2}$ as the carbon source. Only poorly crystalline Fe(III) oxide and Fe(III) citrate are used as electron acceptors for growth. Sulfate, thiosulfate, elemental sulfur, nitrate, fumarate, Mn(IV)oxide, 9,10anthraquinone 2,6-disulfonate and oxygen are not utilized as electron acceptors. With poorly crystalline $\mathrm{Fe}$ (III) oxide anaerobically oxidizes acetate, formate, pyruvate, fumarate, malate, propionate, butyrate, succinate, glycerol, stearate, palmitate peptone and yeast extract. Lactate, L-alanine, glycine, L-proline, arginine, serine, glutamine, asparagine, L-cysteine, aspartic acid, glutamic acid, methanol, ethanol, benzoate are not utilized. Isolated from deepsea hydrothermal field (Ashadze) of the Mid-Atlantic Ridge. The type strain is $\mathrm{SBH}^{\top}$ has been deposited in the Deutsche Sammlung von Mikroorganismen und Zellkulturen under the accession number DSM $21716^{\top}$ and in the All-Russian National Collection of Microorganisms (VKM) under the accession number VKM- $2522^{\top}$. 


\section{Acknowledgements}

This work was supported by grant 09-04-00251-a from the Russian Foundation for Basic Research and by federal programs "Molecular and cell biology" and "The origin of biosphere and the evolution of geobiological systems" of the Russian Academy of Science. We acknowledge the officers and the crew of the R/V Pourquoi Pas? and the ROV Victor operation team. We are also grateful to Dr. Yves Fouquet, Chief Scientist of the SERPENTINE cruise, for his very effective contribution to the success of Ashadze hydrothermal field exploration.

\section{References}

Casamayor, E.O., Massana, R., Benlloch, S., Øvreas, L., Diez, B., Goddard, V.J., Gasol, J.M., Joint, I., Rodriguez-Valera, F., \& Pedrós-Alio, C. (2002). Changes in archaeal, bacterial and eukaryal assemblages along a salinity gradient by comparison of genetic fingerprinting methods in a multipond solar saltern. Environ Microbiol 4, 338-438.

Cole, J. R., Chai, B., Farris, R. J., Wang, Q., Kulam-Syed-Mohideen, A. S., McGarrell, D. M., Bandela, A. M., Cardenas, E., Garrity, G. M. \& Tiedje, J. M. (2007). The ribosomal database project (RDP-II): introducing myRDP space and quality controlled public data. Nucleic Acids Res 35 (Database issue), D169-D172.

Hungate, R. E. (1969). A roll tube method for cultivation of strict anaerobes. Methods Microbiol 3B, 117-132.

Judicial Commission of the International Committee for Systematics of Prokaryotes (2008). Status of strains that contravene Rules 27 (3) and 30 of the International Code of Nomenclature of Bacteria. Opinion 81. Int J Syst Evol Microbiol 58,1755-1763.

Kashefi, K., Holmes, D.E., Barros, J.A. \& Lovley, D.R. (2003). Thermophily in the Geobacteraceae: Geothermobacter erlichii gen. nov., sp. nov., a novel member of the Geobacteraceae from the "Bag City" hydrothermal vent. Appl Environ Microbiol 69, 29852993.

Kashefi, K., Tor, J.M., Holmes, D.E., Gaw Van Praagh, C.V., Reysenbach, A.L. \& Lovley, D.R. (2002). Geoglobus ahangari gen. nov., sp. nov., a novel hyperthermophilic archaeon capable of oxidizing organic acids and growing autotrophically on hydrogen with $\mathrm{Fe}(\mathrm{III})$ serving as the sole electron accepter. Int J Syst Evol Microbiol 52,719-728.

Lane, D. J. (1991). 16S/23S rRNA sequencing. In Nucleic Acid Techniques in Bacterial Systematics, pp. 115-175. Edited by E. Stackebrandt \& M. Goodfellow. Wiley, New York.

Lovley, D.R. \& Phillips, E. J. P. (1988). Novel mode of microbial energy metabolism: organic carbon oxidation coupled to dissimilatory reduction of iron or manganese. Appl Environ Microbiol 54, 1472-1480.

Miroshnichenko, M. L., Slobodkin, A. I., Kostrikina, N. A., L'Haridon, S., Nercessian, O., Spring, S., Stackebrandt, E., Bonch-Osmolovskaya, E. A. \& Jeanthon, C. (2003). 
Deferribacter abyssi sp. nov., an anaerobic thermophile from deep-sea hydrothermal vents of the Mid-Atlantic Ridge. Int J Syst Evol Microbiol 53, 1637-1641.

Muyzer, G., Brinkhoff, T., Nubel, U., Santegoeds, C., Schafer, H. \& Wawer, C. (1997). Denaturing gradient gel electrophoresis (DGGE) in microbial ecology. In: Molecular microbial ecology manual 3.4.4, 1-27. Kluwer academic Publishers.

Muyzer, G., De Waal, E.C. \& Uitterlinden, A.G. (1993). Profiling of complex microbial populations by denaturing gradient gel electrophoresis analysis of polymerase chain reaction-amplified genes coding for 16S rRNA. Appl Environ Microbiol 59, 695-700.

Reysenbach, A.L., Liu, Y., Banta, A.B., Beveridge, T.J., Kirshtein, J.D., Schouten, S., Tivey, M.K., Von Damm, K. \&Voytek, M.A. (2006) Isolation of a ubiquitous obligate thermoacidophilic archaeon from deep-sea hydrothermal vents. Nature 442-444.

Slobodkin, A., Campbell, B., Cary, S.C., Bonch-Osmolovskaya, E.A. \& Jeanthon, C. (2001). Evidence for the presence of thermophilic Fe(III)-reducing microorganisms in deep-sea hydrothermal vents at $13^{\circ} \mathrm{N}$ (East Pacific Rise). FEMS Microbiol Ecol 36, 235-243.

Slobodkin, A.I., Tourova, T.P., Kuznetsov, B.B., Kostrikina, N.A., Chernyh, N.A. \& Bonch-Osmolovskaya, E.A. (1999a). Thermoanaerobacter siderophilus sp. nov., a novel dissimilatory $\mathrm{Fe}(\mathrm{III})$-reducing anaerobic thermophilic bacterium. Int $\mathrm{J}$ Syst Bacteriol 49, 1471-1478.

Slobodkin, A. I., Zavarzina, D. G., Sokolova, T. G. \& Bonch-Osmolovskaya, E. A. (1999b). Dissimilatory reduction of inorganic electron acceptors by thermophilic anaerobic prokaryotes. Microbiology (English translation of Mikrobiologiia) 68, 600-622.

Tor, J.M., Kashefi, K., \& Lovley, D.R. (2001) Acetate oxidation coupled to Fe(III) reduction in hyperthermophilic microorganisms. Appl Environ Microbiol 67, 1363-1365.

Woese, C.R., Achenbach, L., Rouvière, P. \& Mandelco, L. (1991). Archaeal phylogeny: reexamination of the phylogenetic position of Archaeoglobus fulgidus in light of certain composition-induced artifacts. System Appl Microbiol 14, 364-371.

Wolin, E.A., Wolin, M.J. \& Wolfe, R.S. (1963). Formation of methane by bacterial extracts. J Biol Chem 238, 2882-2886.

Zavarzina, D.G., Tourova, T.P., Kuznetsov, B.B., Bonch-Osmolovskaya, E.A. \& Slobodkin, A.I. (2002). Thermovenabulum ferriorganovorum gen. nov., sp. nov., a novel thermophilic anaerobic endospore-forming bacterium. Int J Syst Evol Microbiol 52, 1737-1743. 


\section{Figures}

Fig.1. Phylogenetic tree based on 16S rRNA gene sequences indicating the position of isolate $\mathrm{SBH6}^{\top}$ within the representative members of the order Archaeoglobales. The $16 \mathrm{~S}$ rRNA gene sequence of Thermoproteus tenax was included as outgroup. GenBank accession numbers are given in parentheses. Bar, 10 substitutions per 100 nt. Only the bootstrap values higher $70 \%$ are indicated.

\subsection{0}

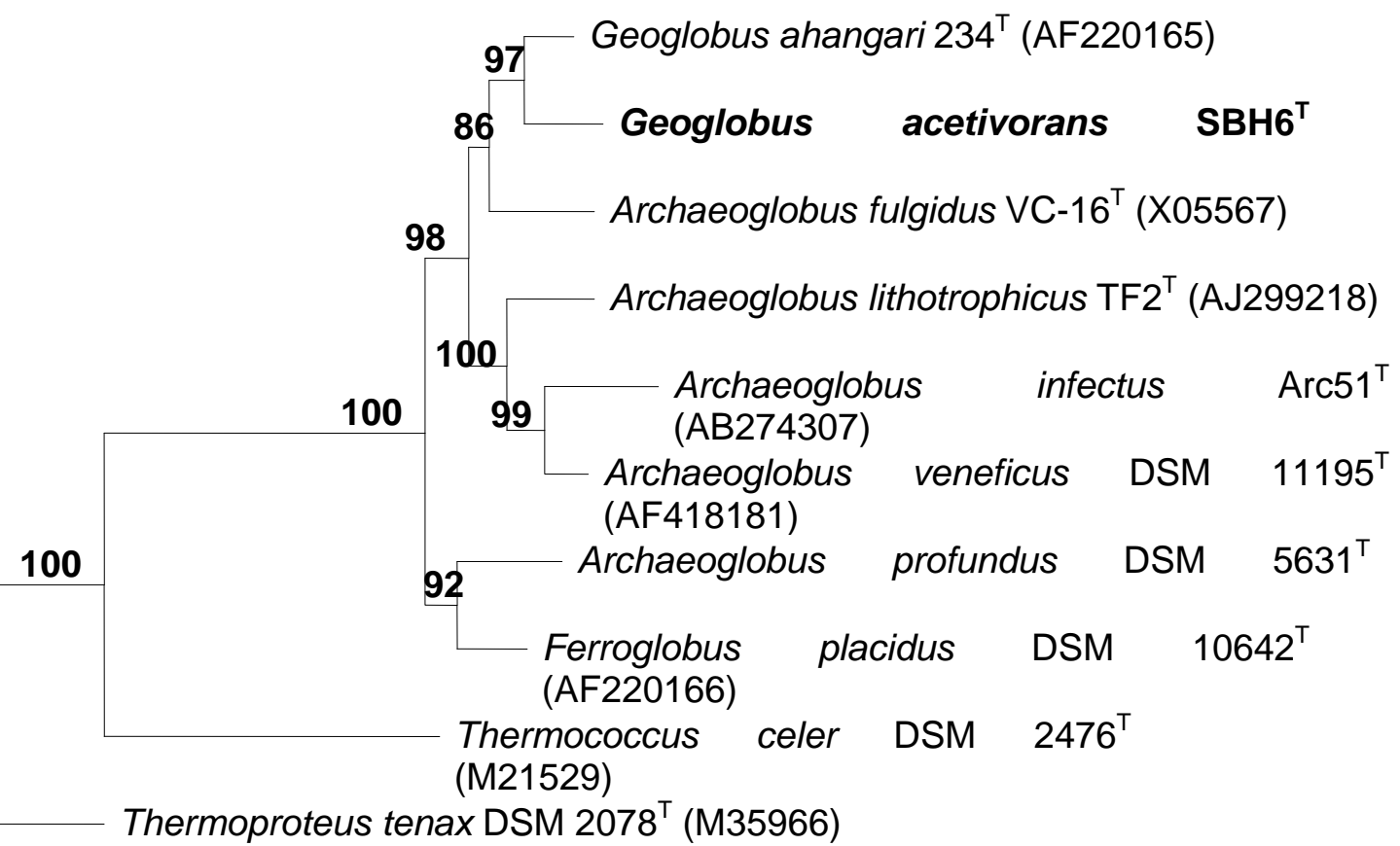

